\title{
The 2D Barcodes Identify the Workpieces by using Microcontroller Interface between Image Processing and PLC Machine
}

\section{Napassadol SINGHATA}

Department of Automation and Robotic Engineering, Faculty of Engineering, Rajamangala University of Technology Krungthep, Bangkok 10120, Thailand

(Corresponding author's e-mail: napassadol.s@mail.rmutk.ac.th)

Received: 19 February 2020, Revised: 21 June 2021, Accepted: 28 June 2021

\begin{abstract}
This paper focuses on 3 main subjects; the first is the presentation and implementation of a PLC concept as a core component to control the system in the industry. The next subject of this work involves some tests to detect 2D barcodes with a web camera on 5 similar workpieces. It is difficult to classify and detect 2D barcodes since they are small about a size of $0.5 \times 0.5 \mathrm{~cm}^{2}$ patterned squares. The last part of the paper presents the implementation of a technique by using a microcontroller to link between a vision system and PLC. This method can be used in an old type of PLC without an additional equipment in the PLC, which can be connected to various types of cameras. The results of the system test show that the vision system can operate in the automatic classifying machine of the PLC controller. The machine vision can classify similar workpieces by using small 2D barcodes with image processing methods. The workpieces are stored in the correct position of 5 boxes in the storage compartment. This method of using a microcontroller interface with image processing and the PLC was successful.
\end{abstract}

Keywords: Barcode, Image Processing, Web camera, Microcontroller, PLC

\section{Introduction}

In industrial automation, the programmable Logic Controller (PLC) is the central controlling unit and is widely used to control a machine in the industry. The operation of the machine can decide like human actions depending on the capability of the sensors because the sensors detect and send signals to the PLC for decision making. In the inspection, a human vision is a current visual inspection tool for inspecting a variety of work such as food, fruit, drug, labels, small electrical components, integrated circuits, and machine tools. In some situations, a misclassifying error is a factor in carelessness, human errors [1], and variability [2]. Moreover, the human eye cannot determine their quality and classify slight changes in color [3] or the size of the workpiece in numeric units [4]. Therefore, the sensor is popularly used for inspection instead of human visual inspection. However, a sensor has a few limitations. First, sensors can inspect workpieces individually at once. Second, sensors cannot detect information in an incorrect orientation. Lastly, in simple tasks of inspection, they cannot operate if part of the components is missing. A vision system is an intelligent sensor for systems that helps to improve productivity by modernizing, increasing work efficiency, and increasing flexibility in the process control [5]. It requires a camera for inspection tasks, including determining their quality and classifying the defect. Moreover, several inspection tasks including determining the color, shape, and size of the workpiece can be done simultaneously using only a camera [6]. Adopting camera systems eliminates limitations in terms of added cost due to the need for multiple sensors and detection of faulty objects only after they exceed several inputs [7]. Many research studies showed the result of the testing and concluded the advantages of machine vision with 5 measures of performance: Accuracy [8-15], speed of response [16], robustness against noise $[17,18]$ and saving inspection time and ease of tuning. It also helps in incorrect orientations 
http://wjst.wu.ac.th

[19], increases consistency in inspection results, and false-positive alarms can be reduced by limiting searching areas [20]. In complex tasks of inspection such as detecting similar objects, the human eyes are difficult to identify. Identifying similar workpieces by making a symbol or attaching tiny tags or labels on the workpiece have become important tools in right object identification and rechecking information. 2D barcodes are small, patterned squares that are appropriate tool to show more details of products, advertisements, and signs. It can include more information, store up to 7,000 digits or 4,000 characters, collect important data to follow the traffic, and provide additional important information. Most 2D barcodes can also be read by mobile devices and phones equipped with basic cameras, since they do not require a high resolution for inspection $2 \mathrm{D}$ barcode tasks. A webcam is low-cost, easy to use, which supports the LabVIEW program. In setting up like an industrial camera and program much the same way therefore, it can be suited to choose in this task. The findings of this study can be incorporated for the development of an industrial inspection. Based on those results, the machine can perform a better recognizing process and make better decisions. However, the vision systems cannot connect to a PLC directly. The modification or upgrade inside a PLC module must be done to integrate a vision system into a PLC system. It is complicated to set up the system. There are also limitations in terms of whether some cameras can be connected with the PLC. In addition, the camera can be chosen to suit the machine. Therefore, this paper presents a method to classify similar workpieces by using 2D barcodes with the technique of using a microcontroller interface between the camera and the PLC. The above-developed methods are very useful and can solve the integration of the visual inspection to a PLC system problem in many ways. In this paper, we propose a hybrid method for automated visual inspection in order to classify similar workpieces. The proposed method consists of 3 stages. In the $1^{\text {st }}$ stage, the inspection stage, 2D barcodes are used to classify and specify the characteristics of workpieces. In the $2^{\text {nd }}$ stage, the conversion stage, the microcontroller converts the characters from the vision system into a digital signal and sends the data to the PLC. In the last stage, the machine stage, the PLC controls the machine to store the workpieces into 5 boxes in the compartment. All of these 3 stages are integrated into a machine vision to classify and store similar workpieces by using 2D barcodes.

The proposed method for vision machine will be introduced in the next section. It illustrates the experimental results of the proposed automated inspection method for machine vision. Conclusion is given in the last section.

\section{Materials and methods}

In the system as in Figure 1, the devices used in the experiment consist of 5 parts 1) a web camera 2) a computer 3) a microcontroller 4) a PLC and 5) a separator machine.

1) A web camera captures the image and sends the data to the computer.

2) A computer transforms the $2 \mathrm{D}$ barcode image into characters. Then, the computer sends the characters to the microcontroller. PLC.

3) A microcontroller converts characters to digital signals. Then, the digital signals are sent to the

4) A PLC is a central system, which receives image signals and feedback signals from the separator machine. It sends the digital control signal to the separator machine to operate.

5) The separator machine consists of 6 parts, which are 1) a pneumatic cylinder 1.2) a pneumatic cylinder 2. 3) a sensor. 4) a conveyor belt. 5) a "Start" button and 6) a "Stop" button.

The pneumatic cylinder 1 pushes the workpiece into the storage compartment.

The pneumatic cylinder 2 is attached to the storage compartment, which has 5 boxes in it. The pneumatic cylinder 2 moves the storage compartment into the position where the workpiece is pushed from the conveyor belt.

The sensor detects the moving workpiece and sends digital signals to the PLC.

The conveyor belt is the equipment that moves the workpieces to terminals.

The "Start" button initiates the process and the "Stop" button terminates the process. 


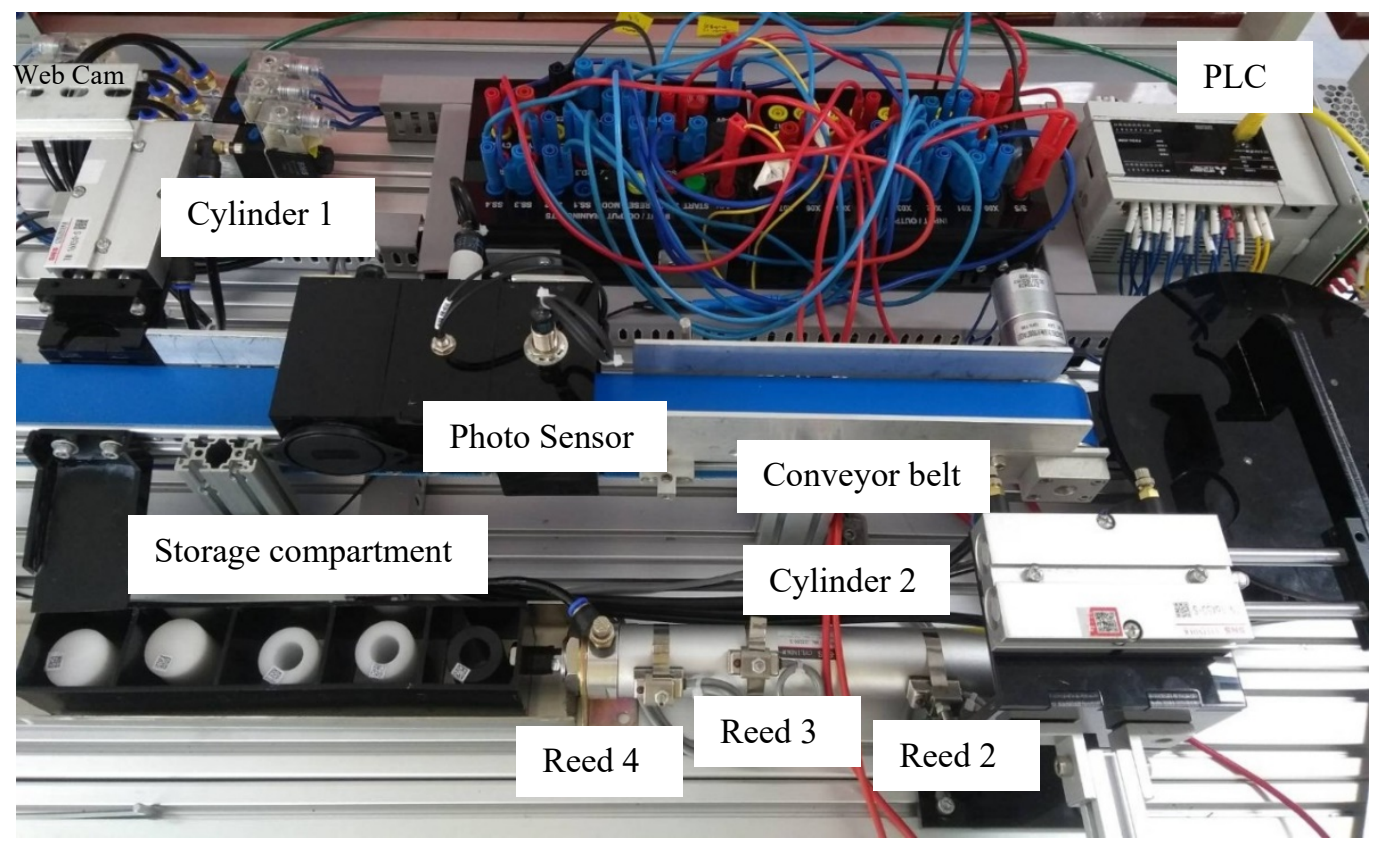

Figure 1 A machine vision to classify the workpieces.

\section{The process of the separator machine}

The workpieces are put on the conveyor belt. Then, the conveyor belt is moved when the "Start" button is pressed. When the workpieces pass in front of the infrared photoelectric sensor, it sends the digital signals to the PLC. Next, the PLC sends a command to the conveyor belt to stop the workpiece in front of the web camera. The web camera then captures the image and sends the data to the computer, which transforms the $2 \mathrm{D}$ barcode image into characters. Later, the characters are sent to the microcontroller. The microcontroller converts characters to digital signals and sends the digital signals back to PLC. When the PLC receives digital signals from the microcontroller, it sends a command to the pneumatic cylinder 2 , which is attached to the storage compartment, to move back and forth. The 2D barcodes, which specify the correct position of the box in the storage compartment are attached to the workpieces. When the web camera scans the workpieces, the pneumatic cylinder 1 kicks the workpieces down the rail and into the specified box in the storage compartment. Finally, the workpieces are in the correct position in the storage compartment-

A software that controls and coordinates the distributed automatic machine systems consists of 3 programs: 1) LabVIEW, 2) Arduino IDE and 3) GX work. The software core of an automated inspection system for image processing should be based on simplified complex functions. A lot of tool techniques are easily supported in vision systems. LabVIEW lies in its ability to quickly facilitate taking measurements. For the generated signal to PLC, microcontroller is used in many operating devices and allows users to write programs for Arduino using $\mathrm{C}++$, with an addition of special methods and functions converted to PLC for reading or further processing. The last program, the most basic function of a programmable controller is to emulate the functions of electromechanical relays. Discrete inputs are given a unique address, and a PLC instruction can test if the input state is on or off. Ladder logic has evolved into a programming language that designs and construct the relay racks as used in manufacturing and process control in automatic machines as in Figure 2. 


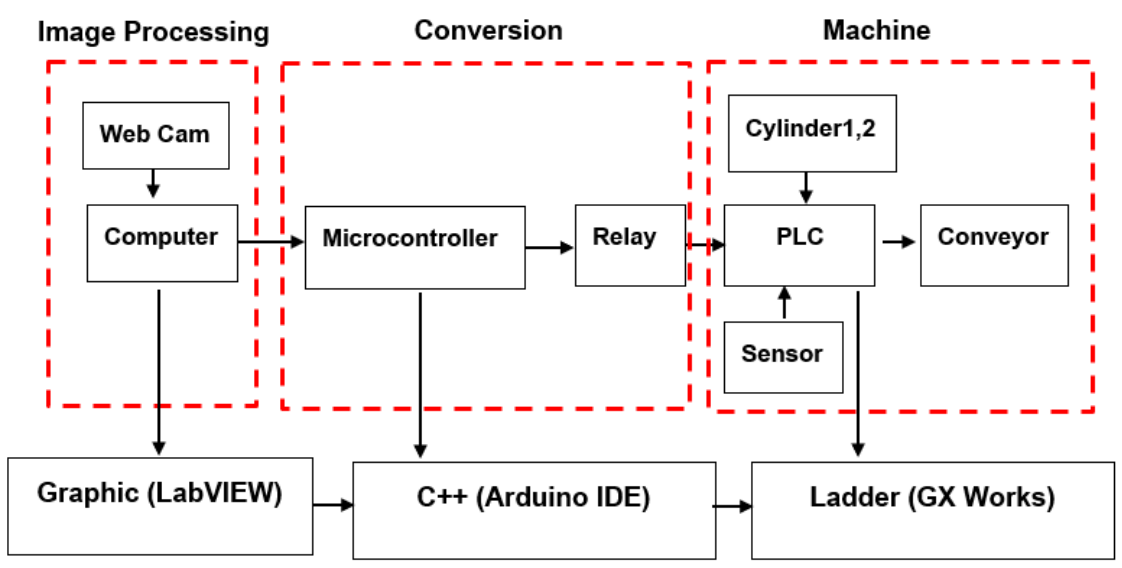

Figure 2 Interface Vision system and PLC machine.

\section{The operation system}

The whole process consists of 4 steps 1) the workpieces 2) image processing with web camera 3) the microcontroller and 4) the PLC. There are 4 similar types of workpieces. Each type is distinct, which is characterized by $2 \mathrm{D}$ barcodes. Type 1 is a white plastic solid cylinder. Type 2 is a white plastic hollow cylinder. Type 3 is a black plastic hollow cylinder, and type 4 is an aluminum cylinder. All workpieces are of the same size (30 $\mathrm{mm}$ in diameter and $40 \mathrm{~mm}$ in height). The workpieces will be stored in a storage compartment that has 5 boxes according to Table 1 .

Table 1 The workpieces are sorted and sorted in the storage compartment.

\begin{tabular}{cccccccc}
\hline Types of workpieces & \multicolumn{2}{c}{ Type 1 } & & Type 2 & Type3 & Type4 \\
\hline Boxes & $\mathbf{1}$ & $\mathbf{2}$ & $\mathbf{3}$ & $\mathbf{4}$ & $\mathbf{5}$ & D \\
\hline \multirow{2}{*}{ Characteristic } & W, & W, & W, & W, & B, & A, \\
& C & C & C & H, & H, & C \\
\hline
\end{tabular}

$\mathrm{A}=$ Aluminum, $\mathrm{B}=$ Black, $\mathrm{C}=$ Cylindrical, $\mathrm{D}=$ Dismissed, $\mathrm{H}=$ Hollow, $\mathrm{W}=$ White

Table 2 The workpieces are sorted and sorted in the storage compartment.

\begin{tabular}{cc}
\hline Parameter & Specification \\
\hline Video mode & $1920 \times 1080$ Pixel \\
framerate & $30 \mathrm{fps}$ \\
Brightness & 124 \\
Contrast & 50 \\
Exposure & 0.25 \\
Focus & 45 \\
White balance & 4896
\end{tabular}


The images in the database are acquired with a web camera to identify the image processing method. These are connected by USB to a computer. The device has been selected to be suitable in this specific application field and this configuration is seen in Table 2.

The steps for image processing are as follows. First, the image is captured by the web camera which sends the image data to the computer. The computer then converts a color image to a gray-scale image. The gray-scale image is decoded into an 8-bit integer ranging from value 0-255. Second, the images are applied with brightness contrast to become clearer and are applied with gamma correction to become sharper. Then, when the computer program detects the 2D barcode, it creates a red hollow square around the 2D barcode on the workpiece. Next, the computer transforms the 2D barcode to characters. Finally, the computer sends characters to the microcontroller as in Figure 3.

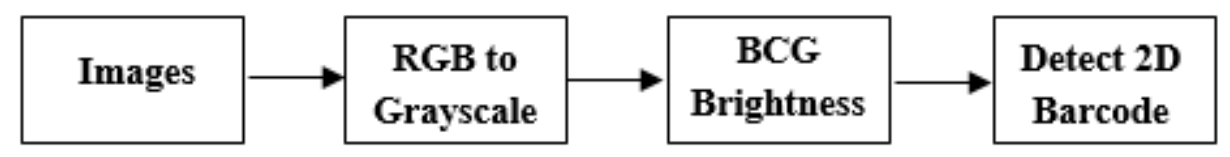

Figure 3 Image processing with web camera.

The image processing is done by specifying the $2 \mathrm{D}$ barcode-data matrix as seen in Figure 4 . The $2 \mathrm{D}$ barcode-data matrix consists of numbers and letters to specify the data and workpiece information. It collects important data to follow the traffic and provides additional important information. The type 1 (boxes 1) workpiece is attached with an "(a)" 2D barcode, the type1 (boxes 2) workpiece is attached with "(b)" 2D barcode, type2 (boxes 3) workpiece is attached with "(c)" 2D barcode, the type2 (boxes 4) workpiece is attached with an "(d)" 2D barcode, and the type3 (boxes 5) workpiece is attached with an "(e)" 2D barcode.

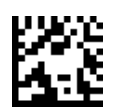

(a)

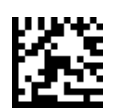

(b)

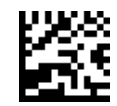

(c)

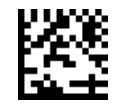

(d)

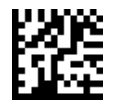

(e)

Figure 4 2D barcode of Image processing.

Third, the image processing is used to detect 2D barcodes, which uses the LabVIEW program as the control vision system. It, then sends characters from the computer to a microcontroller via a serial port USB interface, when the microcontroller receives characters from a computer through serial port communications. It provides an easy and flexible way for an Arduino board to interact with a computer. The image processing decodes 2D barcode from the computer to Arduino board and then Arduino board converts the characters to digital signal. Arduino board is used in operating relays to connect the PLC. The relay has amplified the power 5 to 24 VDC by electrical energy supply subsystems and connects to the input channel of PLC. The microcontroller is easy to interface additional devices, peripherals, and support circuitry by using I/O ports that facilitates and connects between itself and another device more than a computer. 


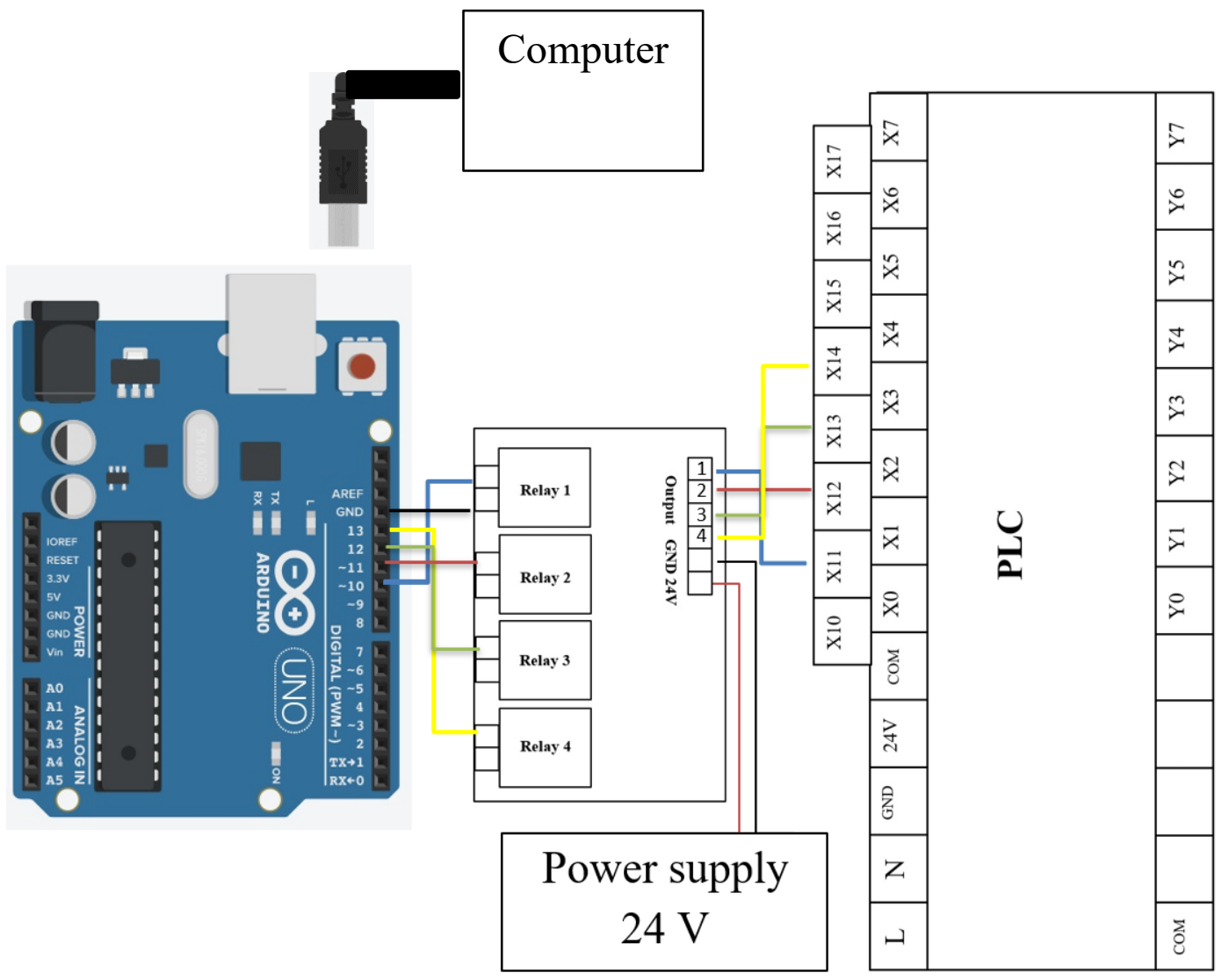

Figure 5 Wiring diagram of microcontroller, relay, and PLC.

A digital signal, which is converted by the Arduino IDE Program, provides information to the PLC with relays. The program is an operation where 4 relays (relay1, relay2, relay3, relay4) are used to implement a keeping workpiece in the boxes. The wiring diagram between microcontroller, relay, and PLC as in Figure 5. The digital signals are converted according to Table 3.

Table 3 Decoding of microcontroller.

\begin{tabular}{ccc}
\hline $\begin{array}{c}\text { Computer } \\
\text { (characters) }\end{array}$ & $\begin{array}{c}\text { Microcontroller } \\
\text { (Logic “HIGH") }\end{array}$ & Boxes of compartment \\
\hline $86 \_$Auto_1 & Relay1 & $\mathrm{a}$ \\
$86 \_$Auto_2 & Relay2 & $\mathrm{b}$ \\
$86 \_$Auto_3 & Relay3 & $\mathrm{c}$ \\
$86 \_$Auto_4 & Relay4 & $\mathrm{d}$ \\
$86 \_$Auto_5 & Relay3, Relay4 & $\mathrm{e}$ \\
\hline
\end{tabular}


http://wjst.wu.ac.th

Fourth, when the PLC receives the digital signals from the microcontroller, it sends a command to the pneumatic cylinder 2 . The pneumatic cylinder 2 is slid and stopped at the rail. Then the pneumatic cylinder 1 pushes the workpiece down on the rail and into the specified box in the storage compartment. Finally, the pneumatic cylinder 1 and 2 are returned to the starting position to prepare for the next command from the PLC. Programmable Logic Controller (PLC), which has a digital electronic device of the microprocessor. It can be used to control automatically the digital logic controller, and load control commands into the memory for storage and execution at any time [21]. The PLC can serve not only the following program's needs, but may also pave the way to further improvements that enable to connect additional devices [22], the input and output of the PLC are connected to the devices as follows.

1. Input $\mathrm{L}$ of the PLC connects to $24 \mathrm{VDC}$ power supply.

2. Input $\mathrm{N}$ of the PLC connects to 0 VDC.

3. Input $\mathrm{S} / \mathrm{S}$ of the PLC connects to $24 \mathrm{VDC}$.

4. Common connect to 0 VDC.

5. The sensors, the microcontroller output, and the actuators are connected to the PLC as shown in Table 4.

Table 4 Connection of PLC.

\begin{tabular}{|c|c|c|c|c|}
\hline \multirow{2}{*}{ Sensor } & \multirow{2}{*}{ Microcontroller and relays } & \multicolumn{2}{|c|}{ PLC } & \multirow{2}{*}{ Actuator } \\
\hline & & Input & Output & \\
\hline Start switch & & $\mathrm{X} 0$ & & \\
\hline Stop switch & & $\mathrm{X} 1$ & & \\
\hline Photoelectric sensor & & $\mathrm{X} 2$ & & \\
\hline Reed switch1 & & $\mathrm{X} 7$ & & \\
\hline Reed switch2 & & $\mathrm{X} 15$ & & \\
\hline Reed switch3 & & $\mathrm{X} 16$ & & \\
\hline \multirow[t]{10}{*}{ Reed switch4 } & & $\mathrm{X} 17$ & & \\
\hline & Pin 10 & $\mathrm{X} 11$ & & \\
\hline & Pin 11 & $\mathrm{X} 12$ & & \\
\hline & Pin 12 & $\mathrm{X} 13$ & & \\
\hline & Pin 13 & $\mathrm{X} 14$ & & \\
\hline & & & Y0 & Conveyor \\
\hline & & & Y1 & Valve1 \\
\hline & & & $\mathrm{Y} 2$ & Valve2 \\
\hline & & & Y3 & Valve3 \\
\hline & & & Y4 & Valve4 \\
\hline
\end{tabular}

Valve 1 = forward cylinder 1 , valve 2 = reverse cylinder 1 , valve $3=$ forward cylinder 2 , valve $4=$ reverse cylinder 2 . 
By writing PLC programs and setting the parameters of the frequency converter, the corresponding frequency conversion control system can be formed so that it is always in a stable operation state, reliability, and can be flexibly configured according to the on-site process conditions [23]. The overall framework of the automation machine system constructed is shown in Figure 6.

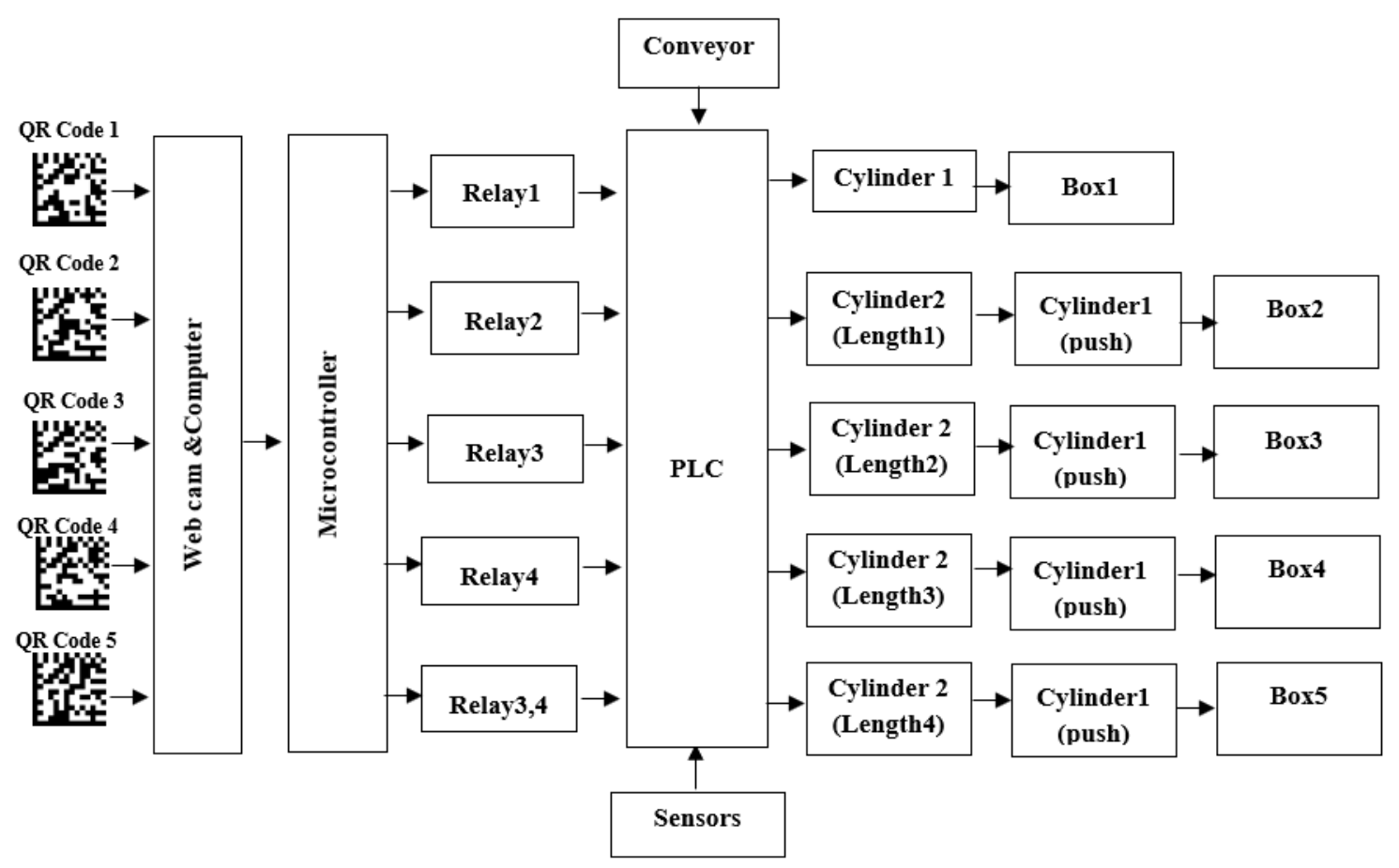

Figure 6 Framework of the automation machine system.

According to Table 4, X 11 PLC input is connected to Pin 10 of the microcontroller. When the PLC receives the digital signal, the pneumatic cylinder 1 is stretched and pushes the workpiece down the rail and into the No.1 box in the storage compartment. Next, the Valve 2 sensor sends a digital signal to the PLC when the pneumatic cylinder 1 stops at the end. Finally, the pneumatic cylinder 1 is returned to the starting position by command of the PLC.

According to Table 4, X 12 PLC input is connected to Pin 11 of the microcontroller. When the PLC receives the digital signal, by the command of the PLC, the pneumatic cylinder 2 pushes the No. 2 box in the storage compartment to the end of the rail. Then, reed switch1 (X 7) sends a digital signal to the PLC which commands the pneumatic cylinder 1 to stretch and push the workpiece down the rail and into the No.2 box in the storage compartment. Next, the Valve 2 sensor sends a digital signal to the PLC when the pneumatic cylinder 1 stops at the end. Finally, the pneumatic cylinder 1 and 2 are returned to the starting position by command of the PLC.

According to Table 4, X 13 PLC input is connected to Pin 12 of the microcontroller. When the PLC receives the digital signal, by the command of the PLC, the pneumatic cylinder 2 pushes the No. 3 box in the storage compartment to the end of the rail. Then, reed switch 2 (X 15) sends a digital signal to the PLC which commands the pneumatic cylinder 1 to stretch and push the workpiece down the rail and into the No.3 box in the storage compartment. Next, the Valve 2 sensor sends a digital signal to the PLC when the pneumatic cylinder 1 stops at the end. Finally, the pneumatic cylinder 1 and 2 are returned to the starting position by command of the PLC. 
According to Table 4, X 14 PLC input is connected to Pin 13 of the microcontroller. When the PLC receives the digital signal, by the command of the PLC, the pneumatic cylinder 2 pushes the No. 4 box in the storage compartment to the end of the rail. Then, reed switch 3 (X 16) sends a digital signal to the PLC which commands the pneumatic cylinder 1 to stretch and push the workpiece down the rail and into the No. 4 box in the storage compartment. Next, the Valve 2 sensor sends a digital signal to the PLC when the pneumatic cylinder 1 stops at the end. Finally, the pneumatic cylinder 1 and 2 are returned to the starting position by command of the PLC.

According to Table 4, X 13 PLC input is connected to Pin 12 of the microcontroller and X 14 PLC input is connected to Pin 13 of the microcontroller. When the PLC receives the digital signals, by the command of the PLC, the pneumatic cylinder 2 pushes the No.5 box in the storage compartment to the end of the rail. Then, reed switch 4 and valve 4 send a digital signal to the PLC which commands the pneumatic cylinder 1 to stretch and push the workpiece down the rail and into the No.5 box in the storage compartment. Next, the Valve 2 sensor sends a digital signal to the PLC when the pneumatic cylinder 1 stops at the end. Finally, the pneumatic cylinder 1 and 2 are returned to the starting position by command of the PLC.

\section{Results and discussion}

This section demonstrates the experimental results. The testing system consists of 2 processes Test 1 - 2D barcode image processing in free orientation and Test 2 - Holistic system testing.

Test 1 - 2D barcode image processing in free orientation.

This experiment shows the image processing testing. Decoding the $2 \mathrm{D}$ barcodes within the camera frame.

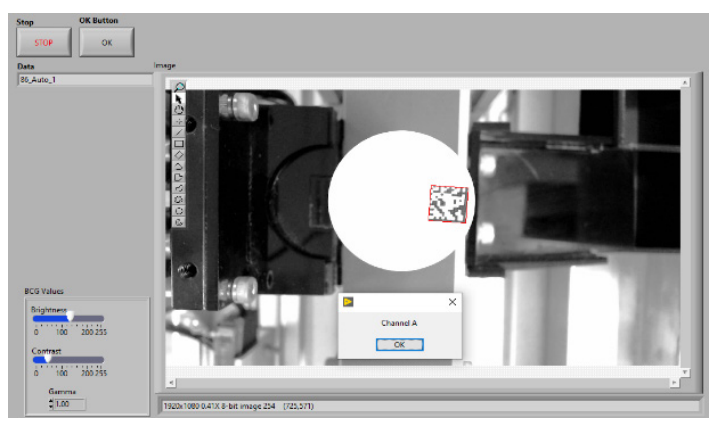

Type1 (boxes 1)

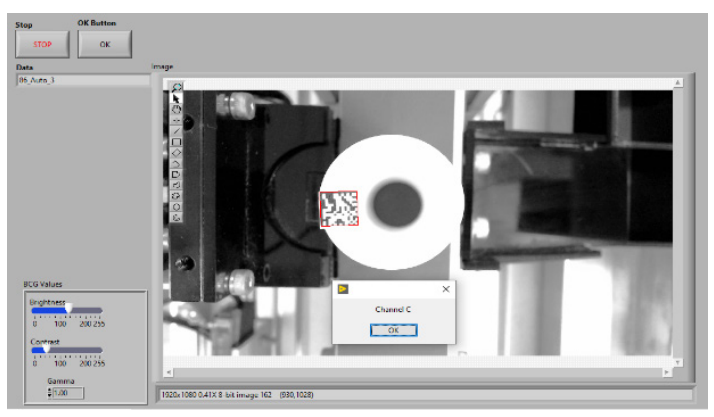

Type2 (boxes 3)

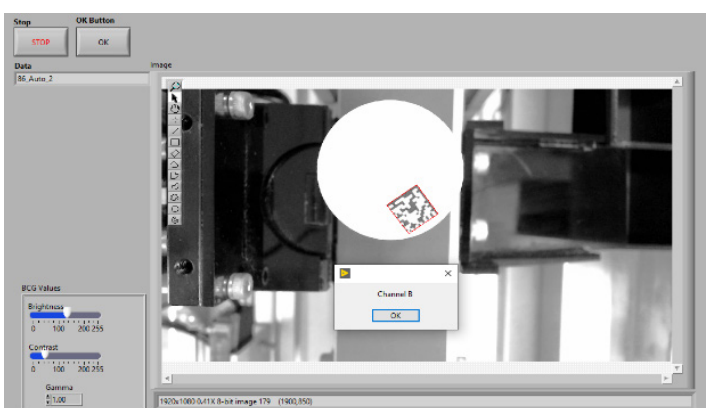

Type1 (boxes 2)

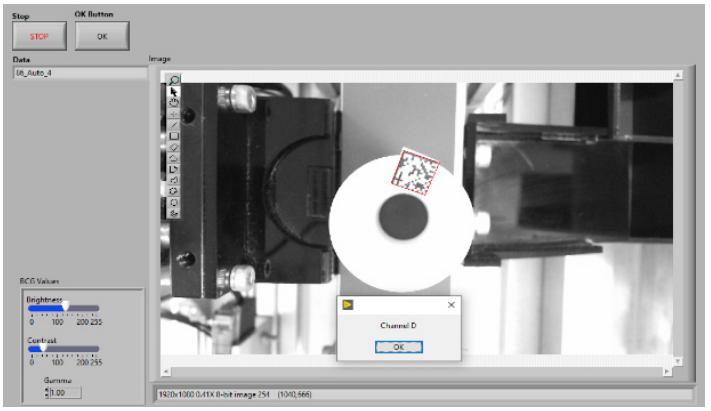

Type2 (boxes 4) 


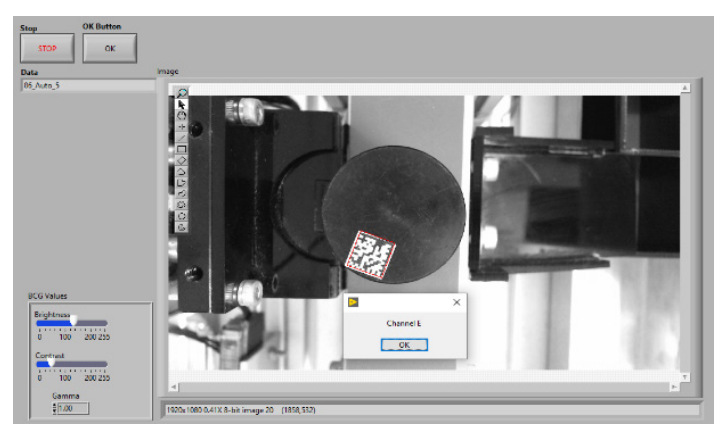

Type3 (boxes 5)

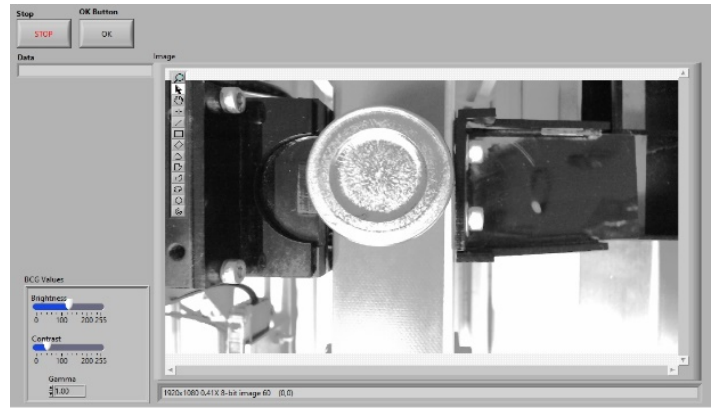

Type4 (Dismissed)

Figure 7 2D barcode image processing in testing 1.

The type 1 (boxes 1) workpiece is attached with an " $86_{-}$Auto _1" 2D barcode, the type1 (boxes 2) workpiece is attached with " 86 _ Auto _2" 2D barcode, type 2 (boxes 3) workpiece is attached with " 86 Auto _3" 2D barcode, the type 2 (boxes 4) workpiece is attached with an "86_Auto _4" 2D barcode, and the type3 (boxes 5) workpiece is attached with an "86_Auto_5" 2D barcode. The workpiece is put on the conveyor belt within the scope of the camera frame. It was found that the red hollow square is created around the 2D barcode image and the message is shown in the image processing as in Figure7. The aluminum workpiece is without a $2 \mathrm{D}$ barcode. The workpiece is put on the conveyor belt within the scope of camera frame. It was found that the red hollow square is not created and the message is not displayed in the image processing as in type4 (Dismissed).

\section{Test 2 - Holistic system testing}

This experiment shows the holistic system testing. The system is tested 5 times. In each test, 5 workpieces are put in a random position on the conveyor belt. The workpieces are slid to the rail and then are stored in 5 boxes in the storage compartment as in Figure 8. The design of the test is according to Table 5.

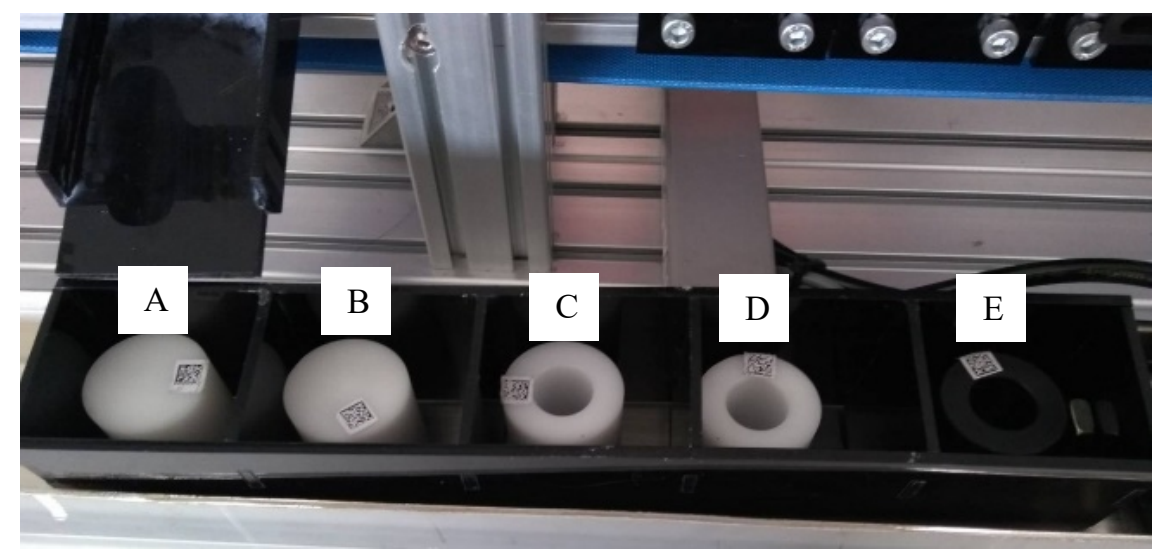

Figure 8 The workpieces in the boxes compartment. 
Table 5 The design of the random the workpieces testing.

\begin{tabular}{|c|c|c|c|c|c|c|}
\hline \multirow{2}{*}{ Number of testing } & \multirow{2}{*}{ Type } & \multicolumn{5}{|c|}{ Workpieces } \\
\hline & & $\mathbf{W}, \mathbf{C} 1$ & $\mathbf{W}, \mathbf{C 2}$ & $\mathbf{W}, \mathbf{H}, \mathbf{C} 1$ & $\mathbf{W}, \mathbf{H}, \mathbf{C 2}$ & $\mathbf{B}, \mathbf{H}, \mathbf{C}$ \\
\hline \multirow[b]{2}{*}{1} & workpiece position & 1 & 2 & 3 & 4 & 5 \\
\hline & result & $\checkmark$ & $\checkmark$ & $\checkmark$ & $\checkmark$ & $\checkmark$ \\
\hline \multirow[b]{2}{*}{2} & workpiece position & 2 & 4 & 5 & 3 & 1 \\
\hline & result & $\checkmark$ & $\checkmark$ & $\checkmark$ & $\checkmark$ & $\checkmark$ \\
\hline \multirow[b]{2}{*}{3} & workpiece position & 3 & 5 & 4 & 1 & 2 \\
\hline & result & $\checkmark$ & $\checkmark$ & $\checkmark$ & $\checkmark$ & $\checkmark$ \\
\hline \multirow[b]{2}{*}{4} & workpiece position & 4 & 1 & 2 & 5 & 3 \\
\hline & result & $\checkmark$ & $\sqrt{ }$ & $\checkmark$ & $\checkmark$ & $\checkmark$ \\
\hline \multirow[b]{2}{*}{5} & workpiece position & 5 & 3 & 1 & 2 & 4 \\
\hline & result & $\checkmark$ & $\checkmark$ & $\checkmark$ & $\checkmark$ & $\checkmark$ \\
\hline
\end{tabular}

$\checkmark$ indicated that the workpiece is put in the correct box of the storage compartment.

In the $1^{\text {st }}$ test, 5 workpieces are put in position 1 , position 2 , position 3 , position 4 , and position 5 . It was found that the machine can put these 5 workpieces into the box in the storage compartment correctly, according to testing No.1 in Table 5. In the $2^{\text {nd }}$ test, 5 workpieces are put in position 2, position 4 , position 5 , position 3 and position 1 . It was found that the machine can put these 5 workpieces into the box in the storage compartment correctly, according to testing No.2 in Table 5 . In the $3^{\text {rd }}$ test, 5 workpieces are put in position 3 , position 5 , position 4 , position 1 , and position 2 . It was found that the machine can put these 5 workpieces into the box in the storage compartment correctly, according to testing No.3 in Table 5. In the $4^{\text {th }}$ test, 5 workpieces are put in position 4, position 1, position 2, position 5 , and position 3 . It was found that the machine can put these 5 workpieces into the box in the storage compartment correctly, according to testing No.4 in Table 5. In the $5^{\text {th }}$ test, 5 workpieces are put in position 5 , position 3 , position 1 , position 2 , and position 4 . It was found that the machine can put these 5 workpieces into the box in the storage compartment correctly, according to testing No.5 in Table 5.

According to Figures 7, even if each of the 5 workpieces has a $2 \mathrm{D}$ barcode on different positions. The image processing can successfully detect the $2 \mathrm{D}$ barcode and can create the red hollow square around the 2D barcode image to correctly classify that workpiece. In summary to Table 5, even if the workpieces are put in any position, the camera can successfully detect the $2 \mathrm{D}$ barcode on the workpiece and the system can classify the workpieces and correctly put them into the designated box in the storage compartment in all tests. The results show that when the workpiece is put on the conveyor belt within the scope of the camera frame, the image processing can decode the 2D barcodes even though the barcode position on the workpieces is in free orientation. Then the workpieces are stored in the correct position of 5 boxes in the storage compartment. Therefore, it was shown that this method of using a microcontroller interface with the image processing and the PLC was successful. The machine vision can classify similar workpieces by using small 2D barcodes with image processing methods. 
http://wjst.wu.ac.th

\section{Conclusions}

In the machine vision, the image processing detects the 2D barcode on the workpieces. It decodes the $2 \mathrm{D}$ barcode correctly even though the $2 \mathrm{D}$ barcode position on the workpiece is in free orientation and randomization without workpiece sequence on the workpiece the conveyor belt. In addition, the camera can send signals to the computer. Then the computer sends the characters to the microcontroller. The microcontroller converts the characters to the digital signal and sends the digital signal to the PLC, which controls the machine to store the workpieces correctly. The microcontroller is the connector between the PLC and image processing. It diminishes the process without having to add additional devices or modify the PLC functions. This will reduce the PLC errors. The image processing can be used instead of single or multiple sensors to inspect the workpieces by only editing the code appropriately to specific types of detection. In addition, if a new workpiece is added to the image processing system, the camera can recognize those parts by extra programming, without having to purchase any sensor or equipment. It reduces the costs and complexity of the system that would occur in adding devices to the original system to allow the machine to work according to the increasing requirements. Therefore, the vision machine provides 1 alternative for an automated, non-destructive, and reduced processing time. The machine vision can classify similar workpieces by using small $2 \mathrm{D}$ barcodes with image processing methods. The findings of this study can be incorporated to develop an inspection of automation systems and provide an interesting method to develop the machine to interface between the vision system and PLC.

This system merges analyses of different types even if the object is small. It is an interesting method that allows real-time classification at a small process and is difficult to classify by using human eyes, especially identifying similar workpieces by making a symbol or attaching tiny barcodes on the workpiece. The complexity of decoding the barcode is a problem for human inspectors, which might take a long time. Therefore, this is an interesting method to develop the machine to operate with an automatic system.

\section{Acknowledgements}

The authors would like to thank the Rajamangala University of Technology Krungthep for supporting the equipment for this research.

\section{References}

[1] H Wang, Z Xiong, AM Finn and Z Chaudhry. A context-driven approach to image-based crack detection. Mach. Vis. Appl. 2016; 27, 1103-14.

[2] JB Li, WQ Huang and CJ Zhao. Machine vision technology for detecting the external defects of fruits - a review. Imag. Sci. J. 2015; 63, 241-51.

[3] SM Iqbal, A Gopal, PE Sankaranarayanan and AB Nair. Classification of selected citrus fruits based on color using machine vision system. Int. J. Food Properties 2016; 19, 272-88.

[4] GC Deac, CN Deac, CL Popa, M Ghinea, CE Cotet. Machine vision in manufacturing processes and the digital twin of manufacturing architectures. In: Proceedings of the $28^{\text {th }}$ DAAAM International Symposium on Intelligent Manufacturing and Automation. Vienna, Austria, 2017, p. 733-6.

[5] MG Hudedmani, RM Umayal, SK Kabberalli and R Hittalamani. Programmable Logic Controller (PLC) in automation. Adv. J. Graduate Res. 2017; 2, 37-45,

[6] V Chauhan and B Surgenor. Fault detection and classification in automated assembly machines using machine vision. Int. J. Adv. Manuf. Tech. 2017; 90, 2491-512.

[7] DB Perng, HW Liu and SH Chen. A vision-based LED defect auto-recognition system. Nondestr. Test. Eval. 2014; 29, 315-31.

[8] CM Yeum and SJ Dyke. Vision-based automated crack detection for bridge inspection. Comput. Aided Civ. Infrastruct. Eng. 2015; 30, 759-70.

[9] JF Lopes, L Ludwig, DF Barbin, MVE Grossmann and S Barbon. Computer vision classification of barley flour based on spatial pyramid partition ensemble. Sensors 2019; 19, 2953. 
http://wjst.wu.ac.th

[10] M Rokunuzzaman and HPW Jayasuriya. Development of a low cost machine vision system for sorting of tomatoes. Agr. Eng. Int. CIGR J. 2013; 15, 173-80.

[11] TH Sun, FC Tien, FC Tien, RJ Kuo. Automated thermal fuse inspection using machine vision and artificial neural networks. J. Intell. Manuf. 2016; 27, 639-51.

[12] A Azizi, Y Abbaspour-Gilandeh, M Nooshyar and A Afkari-Sayah. Identifying potato varieties using machine vision and artificial neural networks. Int. J. Food Properties 2016; 19, 618-35.

[13] MS El-Faki, Y Song, N Zhang, HA El-Shafie and P Xin. Automated detection of parasitized Cadra cautella eggs by Trichogramma bourarachae using machine vision. Int. J. Agr. Biol. Eng. 2018; 11, 94-101.

[14] WY Wu, CW Hung, WB Yu. The development of automated solder bump inspection using machine vision techniques. Int. J. Adv. Manuf. Tech. 2013; 69, 509-23.

[15] M Nagle, K Intani, G Romano, B Mahayothee, V Sardsud and J Müller. Determination of surface color of "all yellow" mango cultivars using computer vision. Int. J. Agr. Biol. Eng. 2016; 9, 42-50.

[16] JA Alvarez-Bermejo, C Giagnocavo, Li Ming, EC Morales, DPM Santos and Y Xinting. Image processing methods to evaluate tomato and zucchini damage in post-harvest stages. Int. J. Agr. Biol. Eng. 2017; 10, 126-33.

[17] AS Prabuwono, W Usino, L Yazdi, AH Basori, A Bramantoro, I Syamsuddin, A Yunianta and KHS Allehaibi. Automated visual inspection for bottle caps using fuzzy logic. TEM J. 2019; 8, 107-12.

[18] ANJ Raj, R Sundaram, VGV Mahesh, Z Zhuang and A Simeone. A multi-sensor system for silkworm cocoon gender classification via image processing and support vector machine. Sensors 2019; 19, 2656.

[19] DT Lin, MC Lin and KY Huang. Real-time automatic recognition of omnidirectional multiple barcodes and DSP implementation. Mach. Vis. Appl. 2011; 22, 409-19.

[20] L Liu, Z Li, Y Lan, Y Shi, Y Cui. Design of a tomato classifier based on machine vision. PLoS One 2019; 14, e0219803.

[21] YH Cheng, PJ Chao, HY Liang and CN Kuo. Smart home environment management using programmable logic controller. Eng. Lett. 2020; 28,1174-81.

[22] PP Horváth, TI Erdei and G Husi. Restoration and PLC control of a material handling MP-9S industrial manipulator platform. Ann. Univ. Oradea Facsicle Manag. Technol. Eng. 2019; 29,1-5.

[23] M Gao. Application analysis of PLC technology in automatic control of ship auxiliary machinery. $J$. Coast. Res. 2020; 115, 130-2. 